\title{
Erratum to: Estimating Aerodynamic Parameters of Urban-Like Surfaces with Heterogeneous Building Heights
}

\author{
J. T. Millward-Hopkins - A. S. Tomlin • L. Ma • \\ D. Ingham - M. Pourkashanian
}

Published online: 27 September 2011

(C) Springer Science+Business Media B.V. 2011

\section{Erratum to: Boundary-Layer Meteorol DOI 10.1007/s10546-011-9640-2}

The text beneath Eq. 16, including Eq. 17, should read: "Below $h_{\mathrm{m} \text {-eff }}$, the drag contribution is estimated by the same method as was used for uniform arrays:

$$
F_{\mathrm{D} 1}=0.5 \rho \hat{U}_{\mathrm{hm} \text {-eff }}^{2} C_{\mathrm{D}} A_{\mathrm{f}}^{*}\left(h<h_{\text {m-eff }}\right)
$$

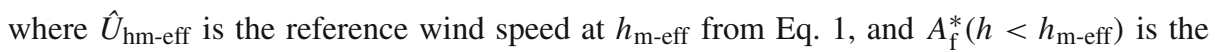
unsheltered frontal area of the blocks below $h_{\text {m-eff." }}$

The online version of the original article can be found under doi:10.1007/s10546-011-9640-2.

J. T. Millward-Hopkins · A. S. Tomlin $(\bowtie) \cdot$ L. Ma · D. Ingham · M. Pourkashanian School of Process, Environmental and Materials Engineering, University of Leeds, Leeds, LS2 9JT, UK e-mail: A.S.Tomlin@leeds.ac.uk 